\title{
Laparoscopic Radical Cholecystectomy for Primary or Incidental Early Gallbladder Cancer: The New Rules Governing the Treatment of Gallbladder Cancer
}

\author{
Gaetano Piccolo ${ }^{1}$ and Guglielmo Niccolò Piozzi ${ }^{2}$ \\ ${ }^{1}$ Department of Surgery, University of Catania, Via S. Sofia 78, 95123 Catania, Italy \\ ${ }^{2}$ Department of Surgery, Università Degli Studi di Milano, Via Festa del Perdono 7, 20122 Milano, Italy \\ Correspondence should be addressed to Gaetano Piccolo; schaky@hotmail.it
}

Received 7 February 2017; Accepted 15 May 2017; Published 11 June 2017

Academic Editor: Piero Chirletti

Copyright (c) 2017 Gaetano Piccolo and Guglielmo Niccolò Piozzi. This is an open access article distributed under the Creative Commons Attribution License, which permits unrestricted use, distribution, and reproduction in any medium, provided the original work is properly cited.

\begin{abstract}
Aim. To evaluate the technical feasibility and oncologic safety of laparoscopic radical cholecystectomy (LRC) for primary or incidental early gallbladder cancer (GBC) treatment. Methods. Articles reporting LRC for GBC were reviewed from the first case reported in 2010 to 2015 (129 patients). 116 patients had a preoperative diagnosis of gallbladder cancer (primary GBC). 13 patients were incidental cases (IGBC) discovered during or after a laparoscopic cholecystectomy. Results. The majority of patients who underwent LRC were pT2 (62.7\% GBC and 63.6\% IGBC). Parenchyma-sparing operation with wedge resection of the gallbladder bed or resection of segments $\mathrm{IVb}-\mathrm{V}$ were performed principally. Laparoscopic lymphadenectomy was carried out according to the reported depth of neoplasm invasion. Lymph node retrieved ranged from 3 to 21 . Some authors performed routine sampling biopsy of the inter-aorto-caval lymph nodes (16b1 station) before the radical treatment. No postoperative mortality was documented. Discharge mean day was POD 5th. 16 patients had post operative morbidities. Bile leakage was the most frequent post-operative complication. 5 y-survival rate ranged from 68.75 to 90.7 months. Conclusion. Laparoscopy can not be considered as a dogmatic contraindication to GBC but a primary approach for early case (pT1b and pT2) treatment.
\end{abstract}

\section{Introduction}

Gallbladder cancer (GBC) is the most frequent neoplasm of the biliary tract [1]. GBC has a great worldwide incidence variability in correlation with both geographic and ethnic features.

Higher rates of GBC are observed in South America (especially Chile), Indian subcontinent, Japan, and Korea [2] and, in many cases, this is due to a higher incidence of S. typhi/paratyphi infection in these countries [3-5].

Nowadays, thanks to the widespread use of ultrasound and laparoscopic cholecystectomy, GBC is diagnosed at an earlier stage with a consequent change in patients' management and outcome.

According to literature, the occurrence of IGBC ranges between 0.19 and $2.8 \%$ [6] with almost half of these cases detected after laparoscopic cholecystectomy for benign diseases (polyps, gallstones, and cholecystitis) [7]. IGBC are usually at an earlier pathological stage with consequent increased long-term survival $[8,9]$.

Simple cholecystectomy may be an adequate treatment only for earlier stages (pTis and pT1a); however, radical resection, including hepatic resection and regional lymphadenectomy, is the only chance of cure associated with demonstrated long-term survival for $\mathrm{pT} 1 \mathrm{~b}$ and later stages. For many years, the use of laparoscopy in GBC was restricted to staging purposes only.

The most important concerns that led to a preliminary nihilistic approach were as follows: the feasibility of achieving an adequate hepatectomy and lymphadenectomy and the risk of intraoperative peritoneal dissemination with possible port site recurrences. 
Recently, few reports have shown the feasibility of laparoscopic radical resection for early gallbladder cancer; however, laparoscopic surgery of the biliary tract still remains a challenging procedure requiring significant experience in both laparoscopy and liver surgery.

\section{Materials and Methods}

2.1. Literature Search. MEDLINE and PubMed searches were performed using the key words "laparoscopic treatment of primary gallbladder cancer", "radical laparoscopic cholecystectomy", and "incidental gallbladder cancer" in order to identify relevant articles published in literature from the first case reported in 2010 to the last case reported in 2015.

Reference lists from the articles were reviewed to identify additional relevant articles. All studies that contained materials applicable to the topic were considered.

Retrieved manuscripts (case reports and series) were reviewed by the authors, and the data were extracted using a standardized collection tool. The extracted data included general information (number of patients treated, patients' age, and study recruitment period), technical aspects (number of operative instruments used, type of hepatic resection, number of lymph node retrieved, time of operation, and total blood loss), and, if available, oncologic outcomes.

2.2. Statistical Analysis. In contrast to classic meta-analyses, the outcome is defined here as the percentages of an event (without comparison) in pseudocohorts of observed patients. Overall proportions can be estimated from the weighted mean of percentages measured in each study. The weight in this case is derived from the number of subjects included in the study out of the total number of subjects in all studies, which is inverse of the variance in the classic meta-analyses.

The confidence interval is calculated through the use of the normal distribution to approximate the binomial probabilities given that the condition "product of the probability and sample size (np) is more than 5 " is fulfilled.

\section{Results}

Our preliminary review identified 124 papers considered potentially relevant for our analysis. Computer-assisted filtering data allowed to exclude non-English papers and nonavailable full-text articles $(n=14)$. The titles of the 110 retrieved papers were examined by two authors (GP and GNP) who excluded nonpertinent papers. 38 articles were suggestive for our aim, but only 9 articles (including 129 patients) reported a total laparoscopic approach for primary or incidental GBC treatment (Figure 1).

Three articles are case reports while six are retrospective or prospective cohort studies (Table 1). A total of 116 patients had a preoperative suspicion or diagnosis of gallbladder carcinoma, while 13 were incidental gallbladder cancer discovered after a laparoscopic cholecystectomy.

3.1. Radical Laparoscopic Cholecystectomy for Primary GBC. At the time of this review, only 7 articles reported a radical laparoscopic approach for primary GBC treatment; among them, one is a case report [10], while the others are retrospective or prospective cohort studies [11-16].

In all studies, the majority of patients had a pT2 stage (62.7\%) (Table 2). Itano et al. and Yoon et al. [12, 16] reported the two widest prospective cohort studies, including, respectively, 45 and 16 patients with pathologically proven GBC that underwent primary laparoscopic cholecystectomy. Both authors described a similar treatment protocol (Figure 2).

The inclusion criterion was patients with suspected GBC without evidence of liver invasion or extrahepatic bile duct involvement at enhanced abdominal CT scan and preoperative endoscopic ultrasound (EUS) $[12,16]$. The endoscopic gallbladder scanning was performed from the bulb or the second portion of the duodenum to the antrum using the balloon contact method.

The EUS staging was used to report the macroscopic tumor appearance (peduncolated versus sessile), the wall thickness (localized versus diffuse), and the layer structures of the gallbladder (maintenance or disruption of the outer hyperechoic layer). All patients were then submitted to laparoscopic staging with both optic and ultrasound analyses in order to exclude unresectable conditions as peritoneal dissemination or liver metastases. In case of liver invasion, the laparoscopic procedure was converted to laparotomy.

Patients with no evidence of liver invasion underwent Calot's triangle dissection with frozen section diagnosis of the cystic duct's stump.

If the biopsy proved to be positive, conversion to laparotomy was performed in order to facilitate a biliary tract reconstruction.

Laparoscopic cholecystectomy was completed by en bloc dissection of a thin liver tissue layer around the gallbladder bed $(>1 \mathrm{~cm})$ in order to avoid the risk of bile spillage.

Intraoperative full-thickness frozen biopsy was performed to confirm the depth of tumor invasion.

Laparoscopic lymphadenectomy is then carried out according to the reported depth of the neoplasm invasion $[12,16]$. For pT1b cancer (tumor invades muscular layer), regional lymph node dissection (N1 lymph nodes: hilar, cystic, pericholedochal, perihepatic, and periportal lymph nodes) is the best choice of treatment, while for pT2 cancer (tumor invades the perimuscular connective tissue layer), extraregional lymph node dissection (N2 lymph nodes: periduodenal, peripancreatic lymph nodes and lymph nodes around the inferior mesenteric artery, common hepatic, and celiac artery) is recommended [10-19].

Itano et al. proved that the number of dissected lymph nodes during laparoscopic lymphadenectomy was similar to those following the open approach [12].

There were also no statistically significant differences in either the disease-free or overall survival rate between the two approaches.

The landmark of this treatment protocol is the correct determination of the depth of GBC invasion; therefore, EUS, laparoscopic ultrasound (LUS), and intraoperative pathological examination played a fundamental role in optimal treatment strategy $[11,12,16]$. Other authors $[14,15]$ treated also pT3 stage tumors with routine wedge 


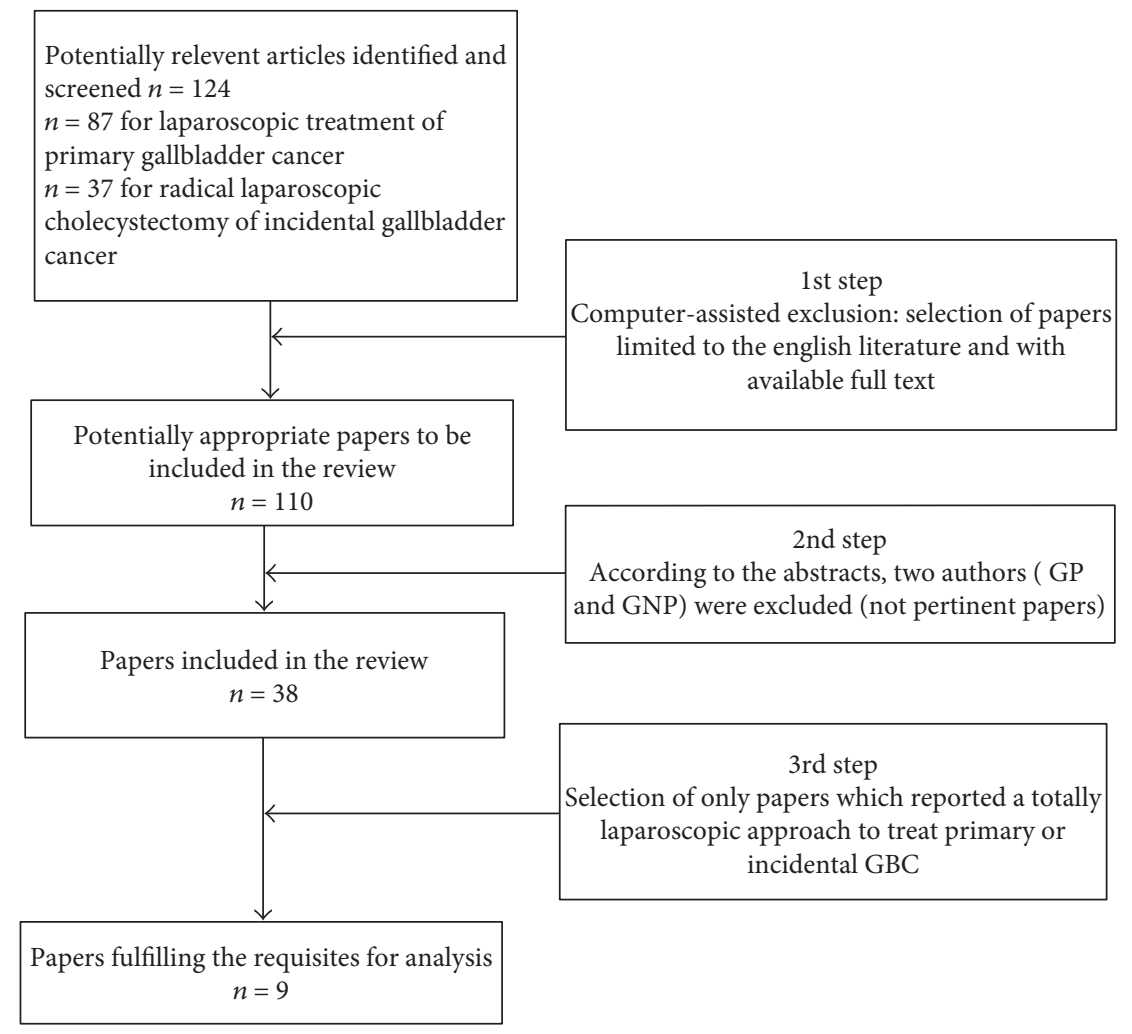

Figure 1: Diagram showing the study methodology and the number of abstracts and articles identified and evaluated during the review process.

TABle 1: Studies.

\begin{tabular}{|c|c|c|c|c|c|}
\hline Author & Date of study & Type of publication & $\begin{array}{c}\text { Number } \\
\text { of patients }\end{array}$ & $\begin{array}{c}\text { Number of } \\
\text { primary GBC }\end{array}$ & $\begin{array}{c}\text { Number of } \\
\text { incidental GBC }\end{array}$ \\
\hline Cho et al. [11] & 2010 & Retrospective comparative study & 18 & 18 & - \\
\hline Gumbs and Hoffman [17] & 2010 & Case report & 1 & - & 1 \\
\hline Gumbs and Hoffman [10] & 2010 & Case report & 1 & 1 & - \\
\hline Itano et al. [12] & $2007-2013$ & Prospective comparative study & 16 & 16 & - \\
\hline Shirobe and Maruyama [13] & $2001-2013$ & Retrospective study & 11 & 4 & 7 \\
\hline Agarwal et al. [14] & $2011-2013$ & Retrospective comparative study & 24 & 20 & 4 \\
\hline Palanisamy et al. [15] & $2008-2013$ & Retrospective study & 12 & 12 & - \\
\hline Machado et al. [18] & 2015 & Case report & 1 & - & 1 \\
\hline Yoon et al. [16] & 2004-2014 & Prospective cohort study & 45 & 45 & - \\
\hline
\end{tabular}

or segmental hepatic resection of segments $\mathrm{IVb}$ and $\mathrm{V}$ for pT2 cancers. Resection plane was marked using harmonic hook or monopolar diathermy, and deeper parenchyma division was performed using a combination of harmonic scalpel or LigaSure (Table 3).

3.2. Radical Laparoscopic Cholecystectomy for IGBC. Only 13 cases of IGBC are described as full laparoscopically treated in the articles selected in our review. The majority of patients who underwent laparoscopic radical re-resection had a pT2 gallbladder cancer (63.6\%) (Table 4).
Shirobe and Maruyama [13] and Agarwal et al. [14] described, respectively, 7 and 4 cases of IGBC treated with laparoscopic radical cholecystectomy, while Machado et al. and Gumbs et al. described only case reports.

Machado et al. reported a case of a 50-year-old woman with a pT1b IGBC who underwent laparoscopic radical reresection, hepatic resection of segments $\mathrm{IVb}$ and $\mathrm{V}$, and laparoscopic extended hilar lymphadenectomy without the need of biliary reconstruction. All 9 lymph nodes retrieved proved to be negative, and the following 12 months follow-up was negative for recurrence. 
TABle 2: Primary GBC staging.

\begin{tabular}{|c|c|c|c|c|c|c|c|c|}
\hline Author & $\begin{array}{l}\text { Cho et al. } \\
\quad[11] \\
n / \text { total }(\%)\end{array}$ & $\begin{array}{c}\text { Gumbs and } \\
\text { Hoffman [10] } \\
n / \text { otal (\%) }\end{array}$ & $\begin{array}{c}\text { Itano et al. [12] } \\
n / \text { total (\%) }\end{array}$ & $\begin{array}{c}\text { Shirobe and } \\
\text { Maruyama [13] } \\
\text { n/total (\%) }\end{array}$ & $\begin{array}{c}\text { Agarwal } \\
\text { et al. [14] } \\
n / \text { total (\%) }\end{array}$ & $\begin{array}{l}\text { Palanisamy } \\
\text { et al. [15] } \\
n / \text { total (\%) }\end{array}$ & $\begin{array}{l}\text { Yoon et al. } \\
{[16], 2015} \\
n / \text { total (\%) }\end{array}$ & $\begin{array}{c}\text { Weighted } \\
\text { average, } \% \\
(95 \% \mathrm{CI})\end{array}$ \\
\hline $\mathrm{pTis}$ & $2 / 18(11 \%)$ & - & - & - & - & - & $2 / 45(4.4 \%)$ & $6.3 \%(11-1.6)$ \\
\hline pT1a & $2 / 18(11 \%)$ & - & $1 / 16(6.25 \%)$ & - & - & - & $10 / 45(22.2 \%)$ & $16.4 \%(7.6-25.2)$ \\
\hline pT1b & $4 / 18(22 \%)$ & $1 / 1(100 \%)$ & $2 / 16(12.5 \%)$ & $2 / 4(50 \%)$ & $1 / 20(5 \%)$ & - & $8 / 45(17.8 \%)$ & $17.3 \%(10-24.5)$ \\
\hline pT2 & $10 / 18(56 \%)$ & - & $13 / 16(81.25 \%)$ & $2 / 4(50 \%)$ & $11 / 20(55 \%)$ & $11 / 12(91.6 \%)$ & $25 / 45(55.5 \%)$ & $62.7 \%(59.5-65.8)$ \\
\hline pT3 & - & - & - & - & $8 / 20(40 \%)$ & $1 / 12(8.3 \%)$ & - & $28.1 \%(24.4-31.8)$ \\
\hline
\end{tabular}

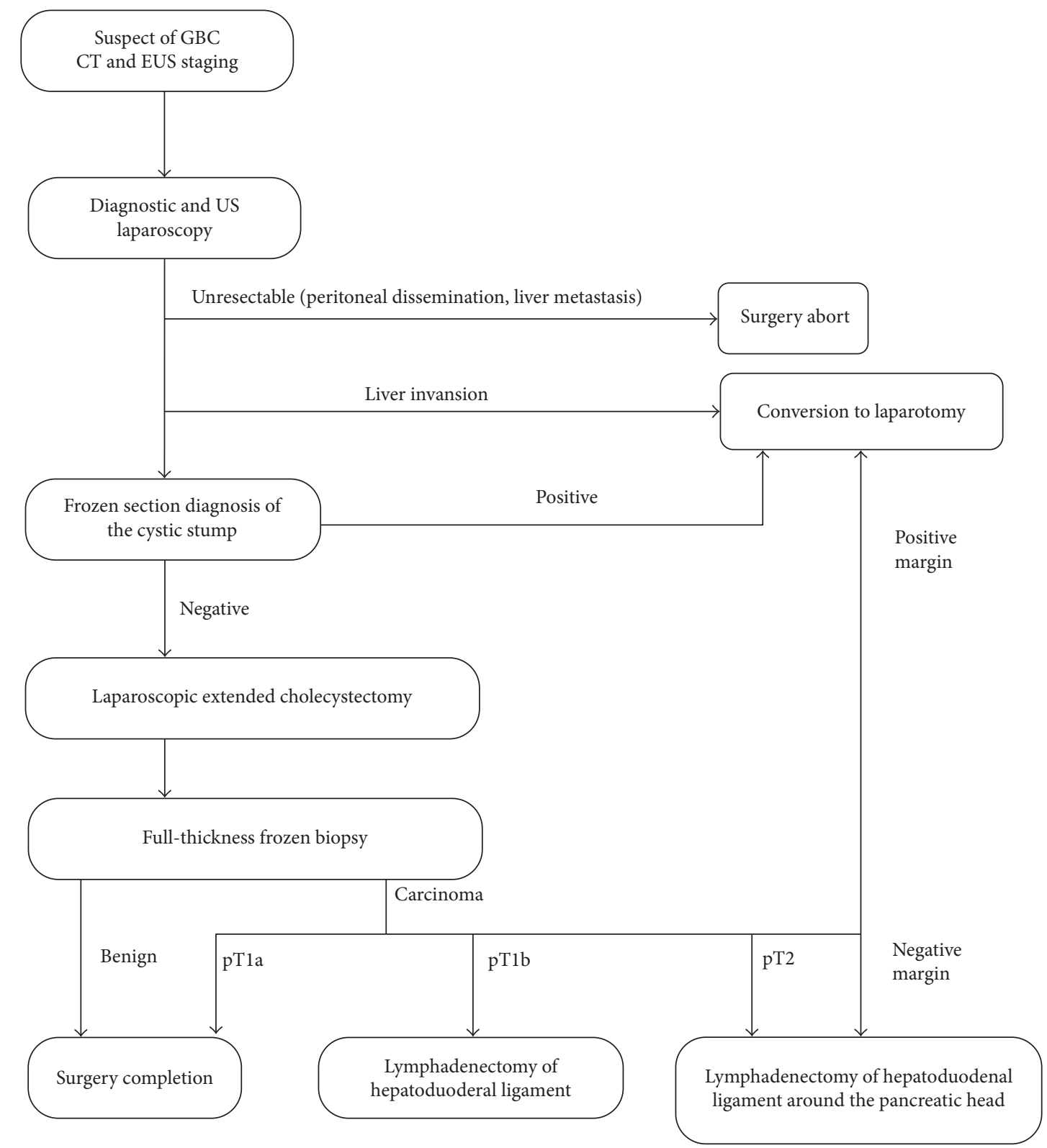

FIGURE 2: Surgical approach for primary GBC. 
TABle 3: Primary GBC surgery details.

\begin{tabular}{|c|c|c|c|c|}
\hline Author & Liver resection & $\begin{array}{l}\text { Devices for liver parenchymal } \\
\text { transaction }\end{array}$ & $\begin{array}{l}\text { Cystic duct } \\
\text { infiltration }\end{array}$ & $\begin{array}{l}\text { Common bile } \\
\text { duct resection }\end{array}$ \\
\hline Cho et al. [11] & $\begin{array}{l}\text { Wedge resection of the } \\
\text { gallbladder bed }(2 \mathrm{~mm})\end{array}$ & - & No & No \\
\hline Gumbs and Hoffman [10] & Segmental resection of IVb and $\mathrm{V}$ & Harmonic scalpel & No & No \\
\hline Itano et al. [12] & $\begin{array}{l}\text { Wedge resection of the } \\
\text { gallbladder bed }(>1 \mathrm{~cm})\end{array}$ & Harmonic scalpel, LigaSure & No & No \\
\hline Shirobe and Maruyama [13] & $\begin{array}{l}\text { Wedge resection of the } \\
\text { gallbladder bed }(1 \mathrm{~cm})\end{array}$ & $\begin{array}{l}\text { Ultrasonic coagulating shear, } \\
\text { BiClamp }\end{array}$ & No & No \\
\hline Agarwal et al. [14] & $\begin{array}{l}\text { Wedge resection of segments } \\
\text { IVb and } \mathrm{V}\end{array}$ & $\begin{array}{l}\text { Harmonic scalpel, LigaSure, } \\
\text { ultrasonic aspirator (CUSA) }\end{array}$ & No & No \\
\hline Palanisamy et al. [15] & $\begin{array}{c}\text { Segmental resection of } \\
\text { IVb and V }\end{array}$ & $\begin{array}{l}\text { Harmonic scalpel, LigaSure, } \\
\text { bipolar diathermy }\end{array}$ & No & No \\
\hline Yoon et al. [16] & $\begin{array}{l}\text { Wedge resection of the gallbladder } \\
\text { bed }(>1 \mathrm{~cm})\end{array}$ & - & No & No \\
\hline
\end{tabular}

TABLE 4: IGBC staging.

\begin{tabular}{lccccc}
\hline Study & $\begin{array}{c}\text { Gumbs and Hoffman [17] } \\
n / \text { total (\%) }\end{array}$ & $\begin{array}{c}\text { Shirobe and Maruyama [13] } \\
n / \text { total (\%) }\end{array}$ & $\begin{array}{c}\text { Agarwal et al. [14] } \\
n / \text { total (\%) }\end{array}$ & $\begin{array}{c}\text { Machado et al. [18] } \\
n / \text { total (\%) }\end{array}$ & Weighted average, \% (95\% CI) \\
\hline pT1a & - & - & - & - & - \\
pT1b & - & $1 / 7(14.3 \%)$ & $2 / 4(50 \%)$ & $1 / 1(100 \%)$ & $33.3 \%(30.4-36.3)$ \\
pT2 & - & $6 / 7(85.7 \%)$ & $1 / 4(25 \%)$ & - & $63.6 \%(62.1-5.2)$ \\
pT3 & $1 / 1(100 \%)$ & - & $1 / 4(25 \%)$ & - & $40 \%(37.1-42.9)$ \\
\hline
\end{tabular}

Gumbs and Hoffman [17] described a pT3 case of IGBC treated with full laparoscopic hepatoduodenal ligament lymphadenectomy and resection of segments $\mathrm{IVb}$ and V; the frozen cystic stump margin was proven positive for tumor spread; therefore, a resection of the common bile duct was performed.

A choledochojejunostomy was made using the laparoscopic approach, the Roux limb was then brought up to the common bile duct and anatomized laparoscopically with a single layer of running 4.0 absorbable suture. Also, Shirobe and Maruyama [13] reported two cases of common bile duct resection and biliary tract reconstruction. For this procedure, minilaparotomy was conducted in the first case, while pure laparoscopic approach was performed in the second patient.

Hepatic resection was performed by all authors but with difference in extension $[10,13,14,18]$. Some authors performed a segmental or a wedge resection of segments IVb and V $[13,14,17]$, while Shirobe et al. [18] performed only a $10 \mathrm{~mm}$-wide resection of the gallbladder bed in order to ensure a complete resection of the gallbladder tumor.

The same author considered the hepatic resection not necessary if the tumor was localized on the peritoneum side of the gallbladder.

The liver resection plane is marked, by all authors, using harmonic hook or monopolar diathermy with LUS confirmation of the anatomical landmarks $[13,14,17,18]$. Liver transection was performed using LigaSure or ultrasonic dissector, while vascular control is enhanced with laparoscopic bipolar device or BiClamp (Table 5).
3.3. Laparoscopic Technique. Surgical technique was fully described by all authors. Patient's position was shown by all authors as supine with reverse Trendelenburg and left lateral tilt (low lithotomy or French approach). The operating surgeon stands between the patient's legs while the assistant surgeon on the patient's left. Shirobe and Maruyama [13] described a different approach with the first operator on the right side, the scope operator between the patient's legs, and the assistant on the left side while Palanisamy et al. [15] instead prefers the scope operator on the patient's right side.

The number of port used was 3 for Cho et al. [11] and 4 for Gumbs and Hoffman [17] and Itano et al. [12] while the other authors used $5[10,12-16,18]$.

The optic port was positioned in the umbilical region while only Gumbs and Hoffman [17] describe a midclavicular positioning below the costal margin. The position of the operative trocars is presented differently by the authors and is showed in Table 6.

A great attention is displayed by all authors in the operative management. The handling of the gallbladder should be minimal, and direct grasping should be avoided in order to reduce the risk of gallbladder rupture with bile spillage and therefore possible tumor cell dissemination.

All authors focus on the need of protected specimen extraction through a plastic bag. The mean length of operation was 276 minutes with a minimum of 90 minutes and a maximum of 441 minutes. The average total blood loss was $210 \mathrm{ml}$ with a minimum of $10 \mathrm{ml}$ and a maximum 
TABLE 5: IGBC surgery details.

\begin{tabular}{|c|c|c|c|c|}
\hline Author & Liver resection & $\begin{array}{l}\text { Devices for liver parenchymal } \\
\text { transaction }\end{array}$ & $\begin{array}{l}\text { Cystic duct } \\
\text { infiltration }\end{array}$ & $\begin{array}{l}\text { Common bile } \\
\text { duct resection }\end{array}$ \\
\hline Gumbs and Hoffman [17] & Segmental resection of IVb and V & Harmonic scalpel & Yes & Yes \\
\hline Shirobe and Maruyama [13] & $\begin{array}{l}\text { Wedge resection of the } \\
\text { gallbladder bed }(1 \mathrm{~cm})\end{array}$ & $\begin{array}{l}\text { Ultrasonic coagulating shear, } \\
\text { BiClamp }\end{array}$ & Yes for $2 / 7$ patients & Yes in 2 patients \\
\hline Agarwal et al. [14] & $\begin{array}{l}\text { Wedge resection of segments } \\
\text { IVb and V }\end{array}$ & $\begin{array}{l}\text { Harmonic scalpel, LigaSure, } \\
\text { ultrasonic aspirator (CUSA) }\end{array}$ & No & No \\
\hline Machado et al. [18] & $\begin{array}{c}\text { Segmental resection of } \\
\text { IVb and V }\end{array}$ & $\begin{array}{c}\text { Harmonic scalpel, LigaSure, } \\
\text { bipolar diathermy }\end{array}$ & No & No \\
\hline
\end{tabular}

of $1500 \mathrm{ml}$. Only one patient in Yoon et al.'s [16] series needed blood transfusion and conversion to laparotomy following portal vein lesion (total intraoperative blood loss: $1500 \mathrm{ml}$ ).

Cho et al. [11] reported two intraoperative complications: one patient suffered bleeding from a torn branch of the main portal vein during node dissection that induced conversion to laparotomy; the other case is an injury of the left hepatic duct during LLA treated with intracorporeal repair and Ttube insertion with full postoperative recovery.

3.4. Laparoscopic Lymphadenectomy. Before proceeding with the radical resection, Agarwal et al. [14] reported to perform a routine sampling biopsy of the interaortocaval lymph node basins (IAC, 16b1 station), with a median number of 2 lymph nodes analyzed (range: 1-3). Also, Palanisamy et al. [15] looked for enlargement of both IAC and celiac group lymph node basins and executed frozen analysis only if enlarged. Agarwal et al. [14] in case of positive biopsy decided to abandon the surgical resection while Palanisamy et al.'s [15] decision is case-bycase with possible defection of the surgical procedure or additional extension in the nodal clearance.

Lymphadenectomy was performed laparoscopically by all authors, and the mean number of lymph node retrieved ranged between 3 and 21 lymph nodes, according to different authors [10-18].

The extent of lymphadenectomy included lymph nodal dissection along the entire length of the hepatic artery from the celiac axis to its bifurcation into right and left hepatic arteries with dissection of the retropancreatic lymph nodes and lymph nodal clearance of the hepatoduodenal ligament including pericholedochal and peri/retroportal lymph nodes.

The circumferential dissection of the hepatoduodenal ligament is completed, and the entire lymph nodal tissue was excised en bloc. Palanisamy et al. [15] proposed an extended lymphadenectomy with duodenal kocherization.

The duodenum was retracted medially to expose the posterior aspect of the head of the pancreas and continued till exposing the right lateral border of the aorta. All fibrofatty tissues, along the posterior-superior aspect of the pancreatic head, were dissected and swept cranially till the right lateral aspect of the vena cava above the insertion of the right renal vein.

Lymphadenectomy was furtherly executed by entering the lesser sac through the gastrohepatic omentum. The origin of the celiac trunk was exposed with excision of the tissues overlaying the common hepatic artery, safeguarding the gastroduodenal artery.

All the tissues cleared from prior dissected areas were swept toward the hepatoduodenal region in order to be included en bloc in the final specimen.

Finally, the hepatoduodenal ligament was opened, portal structures were skeletonized circumferentially, and lymphadenectomy was completed after removing the periportal, pericholedochal, and the lymph nodes along the hepatic proper artery till its bifurcation. All the resected tissues were then kept in a plastic retrieval bag for removal. The entire fibrofatty tissue was cleared from the cystic triangle skeletonizing the portal branches and the hepatic arteries and swept toward the cystic pedicle to be removed later along with the gallbladder and the liver bed. The lymphadenectomy details are showed in Table 7.

3.5. Outcome. None of the series documented postoperative mortality. Discharge mean day was POD 5. An overall 16 patients of the 129 had postoperative morbidities. According to the Clavien-Dindo classification, the classifications are grade I (4 pneumonia, 1 paralitic ileus), grade II (2 voiding difficulty, 2 transient bleeding), and grade IIIa (5 symptomatic intraabdominal fluid accumulation, 2 wound infection). The most frequent postoperative complication reported was bile leakage.

Palanisamy et al. [15] described postoperative bile leakage in two patients: the first patient underwent ERCP and stenting on POD 5, due to persistent high bilious output; the second reported case was treated through US-guided positioning of percutaneous pigtail catheter. Follow-up mean was 35 months (range: 3-119 months). The 5-year survival rate ranged between 68.75 months and 90.7 months $[15,16]$.

Palanisamy et al. [15] showed a 5-year survival rate of $68.75 \%$ with a median follow-up of 51 months; three patients died during the follow-up period (two had node-positive disease and one had pT3 lesion).

Yoon et al. [16], reporting a prospective 10-year study, showed a median follow-up of 60 months (range: 3.5 to 118.9 months). Two patients deceased for tumor recurrence at 21.3 and 30.3 months after surgery while 4 patients died from newly developed neoplasms (HCC, duct cancer, pancreatic cancer, and gastric cancer; at 40.7, 74.8, 97.2, and 98.3 months after surgery, resp.).

The overall and disease-specific 5-year survival rates for the 45 patients were $90.7 \%$ and $94.2 \%$, respectively. The 5year disease-specific survival rate was $100 \%$ for $\mathrm{pT} 1 \mathrm{a}$ patients and pT1b patients and $90.2 \%$ for $\mathrm{pT} 2$ patients. 


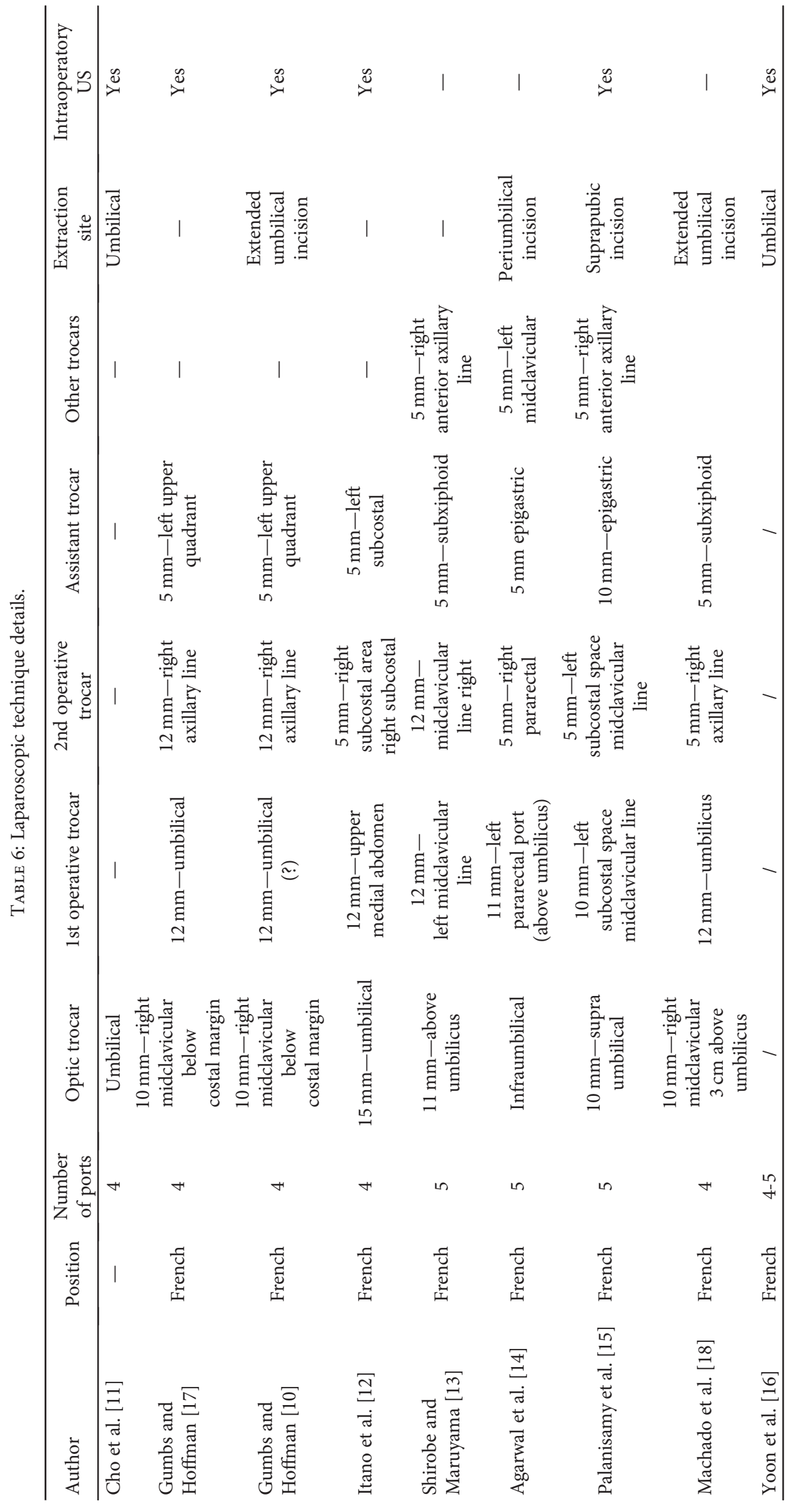


TABLE 7: Lymphadenectomy.

\begin{tabular}{|c|c|c|c|}
\hline Author & IAC sampling biopsy & Station of lymph nodes & $\begin{array}{c}\text { Number of lymph } \\
\text { nodes retrieved }\end{array}$ \\
\hline Cho et al. [11] & - & Pericholedochal, hilar, periportal, and common hepatic & $8(4-21)$ \\
\hline Gumbs and Hoffman [17] & - & Hepatoduodenal & 3 \\
\hline Gumbs and Hoffman [10] & - & Hepatoduodenal & 6 \\
\hline Itano et al. [12] & - & $\begin{array}{l}\text { Hepatoduodenal ligament (if pT1b); hepatoduodenal } \\
\text { ligament and peripancreatic (if pT2) }\end{array}$ & $12.6 \pm 3.1$ \\
\hline Shirobe and Maruyama [13] & - & $\begin{array}{c}\text { Celiac axis, common hepatic, proper hepatic, } \\
\text { hepatoduodenal ligament, posterior surface } \\
\text { of the pancreas }\end{array}$ & $13.3 \pm 2.3$ \\
\hline Agarwal et al. [14] & $2(1-3)$ & $\begin{array}{l}\text { Celiac axis, hepatoduodenal ligament } \\
\text { (pericholedochal and peri/retroportal included), } \\
\text { common hepatic artery, retropancreatic }\end{array}$ & $\begin{array}{c}12.5 \pm 5.4 \\
(\text { Primary GBC: } 13.6 \pm 4.8) \\
(\text { IGBC: } 5.5 \pm 1.7)\end{array}$ \\
\hline Palanisamy et al. [15] & $\begin{array}{l}\text { IAC and celiac } \\
\text { (if enlarged) }\end{array}$ & $\begin{array}{l}\text { Posterior surface of the pancreas head and } \\
\text { right lateral vena cava; celiac axis, hepatoduodenal } \\
\text { ligament, common hepatic artery }\end{array}$ & $8(4-14)$ \\
\hline Machado et al. [18] & - & Extensive hilar and hepatoduodenal ligament & 9 \\
\hline Yoon et al. [16] & - & Hepatoduodenal ligament, common hepatic artery & $7(1-15)$ \\
\hline
\end{tabular}

Shirobe and Maruyama [13] reported a similar finding with a 5 -year survival rate of $100 \%$ for pT1b patients and $83.3 \%$ for pT2 patients.

\section{Discussion}

Gallbladder cancer (GBC) management and outcomes have changed nowadays through worldwide spread of abdominal ultrasound and laparoscopic approach that permits an earlier stage discovery of the disease [6]. For many years, laparoscopic surgery in GBC patients has been contraindicated. Today, GBC and laparoscopy are not two words in contrast. This procedure only does not seem to be a contraindication but also, if correctly performed, may be an elective approach for primary early cases (pT1a, pT1b, and pT2) and a feasible tool for radical re-resection of incidental cases. Survival rate for GBC patients is strictly related to parietal invasion depth of the tumor. Simple cholecystectomy may be an adequate treatment only for earlier stages (pTis and pT1a) [1, 9, 19-22]. Radical cholecystectomy, including hepatic resection with regional lymphadenectomy, is recommended for $\mathrm{pT} 1 \mathrm{~b}$ and later-stage carcinomas as long as the disease appears to be R0 [1, 9, 19-22]. The primary concerns, which led to a preliminary nihilistic approach to laparoscopy, were the feasibility of achieving an adequate hepatectomy and lymphadenectomy, the risk of intraoperative peritoneal dissemination, and possible port site recurrences.

The mainstay of the radical laparoscopic approach results from a perfect evaluation of the depth of the cancer. This depth assessment may be achieved through endoscopic and laparoscopic ultrasound for primary GBC and through accurate finally pathological examination for incidental cases $[12,16]$.

In this review, the majority of patients who underwent laparoscopic radical cholecystectomy had a pT2 stage (62.7\% and $63.6 \%$ for the primary GBC and for the incidental cases, resp.) and only few pT3 stage cases have been treated.
For some authors, tumor invasion into the liver represented a reason to convert the procedure from laparoscopic to open $[12,16]$. However, in the era of major liver resections, the wedge gallbladder bed or hepatic resection of segments $\mathrm{IVb}$ and $\mathrm{V}$ cannot be a concern.

Two aims should be fulfilled during hepatic resection: removal of the tumor that has directly invaded the liver from the gallbladder bed and prevention of micrometastases that may recur around the gallbladder bed.

No consensus is available about the extension of liver resection and whether hepatic resection can prevent liver recurrence.

Nowadays, parenchyma-sparing treatments, such as nonanatomical wedge resection, are preferred to extended ones [10-17].

Wedge resection of the gallbladder bed $(3 \mathrm{~cm})$, if hepatoduodenal ligament invasion and locoregional involvement are excluded, is considered preferable to hepatectomy $[4,20]$.

In case of gallbladder bed invasion, nonanatomical hepatic parenchyma resection with a distal clearance of at least $2 \mathrm{~cm}$ is optimal in order to obtain negative histological margins $[4,20]$.

Lymphadenectomy has an important role in GBC both for staging and as an independent prognostic factor for survival; however, no consensus is available on the lymphadenectomy extension.

Concerns about the accuracy and safety of laparoscopic lymphadenectomy, as the open one, might be related to a surgeon-related variable, dependent mainly on the surgeon's experience and technical skills. For pTis (tumor in situ) and pT1a, simple cholecystectomy, without lymphadenectomy, is considered adequate, although Ogura et al. reported a residual nodal disease in about $2.5 \%$ of pT1a [23]. The dissection of the hepatoduodenal ligamentlymph nodes (hilar, cystic, pericholedochal, perihepatic, and periportal lymph nodes) is considered the treatment of choice for pT1b [24]. 
For pT2 and pT3, extraregional lymph node dissection including periduodenal and peripancreatic lymph nodes and lymph nodes around inferior mesenteric artery, common hepatic, and celiac artery is recommend $[19,25]$.

Questionable is the choice of performed routine sampling or lymphadenectomy of para-aortic lymph nodes that occurs in approximately $19 \%$ of patients with pT2-pT3 GBC [26].

No consensus is available about the prognostic significance of this lymph nodes involvement and if it can be considered a contraindication for radical resection.

According to Murakami et al. [26], no significant difference on overall survival was evidenced among patients with or without metastatic para-aortic lymphatic involvement $(p=0.614)$.

We believe that para-aortic lymph node metastases is not a contraindication for radical resection of gallbladder cancer [27]. Therefore, the positive detection of metastatic paraaortic lymph nodes, during the preliminary pathological examination should not prevent from performing an aggressive surgical procedure and achieving a radical resection [27].

Common bile duct excision and choledochojejunostomy, necessary in case of cystic duct infiltration, are not an absolute contraindication for the laparoscopic approach; however, high technical skills and laparoscopic experience are needed [17].

Port site metastasis is the most common form of peritoneal dissemination after laparoscopic cholecystectomy for GBC and represents the major concern for a laparoscopic approach among surgeons. The prevalence of tumor seeding in port sites is very variable in published series (between 0 and $40 \%$ ), with higher incidences associated with gallbladder perforation at the time of cholecystectomy $[28,29]$.

It has been reported at all stages of GBC and at any of the trocars sites. Port site metastasis appears after latency, between few months and 4 years, implying that subclinical port site disease may be unrecognized if excision is not performed.

However, in a large cohort of patients, from the French registry and the Memorial Sloan Kettering Cancer Center (MSKCC), the authors concluded that port site excision was not associated with improved survival and should not be considered mandatory during definitive surgical treatment of incidental gallbladder cancer $[29,30]$.

\section{Conclusions}

Our study is subjected to a number of limitations, the most important of which is the relatively small group of patients with primary or incidental GBC treated with a total laparoscopic approach. However, in the era of miniinvasive surgery, the rules governing the treatment of GBC are fundamentally changed and laparoscopy does not seem to be not only a contraindication but also, if correctly performed, may be an elective primary approach for the treatment of early cases. The limits of laparoscopy technique are continually redefined by going beyond them every day. Today, laparoscopic approach could be offered to all patients with early resectable disease (pT1b and pT2 cancer).

\section{Additional Points}

Core Tip. This study aims to evaluate the technical feasibility and the oncological safety of laparoscopic radical cholecystectomy (LRC) for primary or incidental early gallbladder cancer (GBC) treatment. In the minimally invasive surgery era, the rules governing the treatment of gallbladder cancer are changing, with laparoscopy not anymore considered a contraindication but, if correctly performed, an elective primary approach for treatment of early cases.

\section{Conflicts of Interest}

The authors declare that they have no conflicts of interest.

\section{Authors' Contributions}

Gaetano Piccolo designed the study. Guglielmo Niccolò Piozzi performed the research. Gaetano Piccolo and Guglielmo Niccolò Piozzi drafted the article. All authors critically reviewed the article and read and approved the contents.

\section{References}

[1] D. Fuks, J. M. Regimbeau, Y. P. Le Treut et al., "Incidental gallbladder cancer by the AFC-GBC-2009 Study Group," World Journal of Surgery, vol. 35, no. 8, pp. 1887-1897, 2011.

[2] S. Misra, A. Chaturvedi, N. C. Misra, and I. D. Sharma, "Carcinoma of the gallbladder," The Lancet Oncology, vol. 4, no. 3, pp. 167-176, 2003.

[3] S. Kumar, S. Kumar, and S. Kumar, "Infection as a risk factor for gallbladder cancer," Journal of Surgical Oncology, vol. 93, no. 8, pp. 633-639, 2006.

[4] G. Gonzalez-Escobedo, J. M. Marshall, and J. S. Gunn, "Chronic and acute infection of the gall bladder by Salmonella typhi: understanding the carrier state," Nature Reviews. Microbiology, vol. 9, no. 1, pp. 9-14, 2011.

[5] Y. D. Walawalkar, R. Gaind, and V. Nayak, "Study on Salmonella typhi occurrence in gallbladder of patients suffering from chronic cholelithiasis - a predisposing factor for carcinoma of gallbladder," Diagnostic Microbiology and Infectious Disease, vol. 77, no. 1, pp. 69-73, 2013.

[6] A. Cavallaro, G. Piccolo, V. Panebianco et al., "Incidental gallbladder cancer during laparoscopic cholecystectomy: managing an unexpected finding," World Journal of Gastroenterology, vol. 18, no. 30, pp. 4019-4027, 2012.

[7] A. Duffy, M. Capanu, G. K. Abou-Alfa et al., "Gallbladder cancer (GBC): 10-year experience at Memorial Sloan-Kettering Cancer Centre (MSKCC)," Journal of Surgical Oncology, vol. 98, pp. 485-489, 2008.

[8] W. J. Zhang, G. F. Xu, X. P. Zou et al., "Incidental gallbladder carcinoma diagnosed during or after laparoscopic cholecystectomy," World Journal of Surgery, vol. 33, no. 12, pp. 2651-2656, 2009.

[9] S. B. Choi, H. J. Han, C. Y. Kim et al., "Incidental gallbladder cancer diagnosed following laparoscopic cholecystectomy," World Journal of Surgery, vol. 33, no. 12, pp. 2657-2663, 2009.

[10] A. A. Gumbs and J. P. Hoffman, "Laparoscopic completion radical cholecystectomy for T2 gallbladder cancer," Surgical Endoscopy, vol. 24, no. 12, pp. 3221-3223, 2010. 
[11] J. Y. Cho, H. S. Han, Y. S. Yoon, K. S. Ahn, Y. H. Kim, and K. H. Lee, "Laparoscopic approach for suspected early-stage gallbladder carcinoma," Archives of Surgery, vol. 145, no. 2, pp. 128-133, 2010.

[12] O. Itano, G. Oshima, T. Minagawa et al., "Novel strategy for laparoscopic treatment of pT2 gallbladder carcinoma," Surgical Endoscopy, vol. 29, no. 12, pp. 3600-3607, 2015.

[13] T. Shirobe and S. Maruyama, "Laparoscopic radical cholecystectomy with lymph node dissection for gallbladder carcinoma," Surgical Endoscopy, vol. 29, no. 8, pp. 2244-2250, 2015.

[14] A. K. Agarwal, A. Javed, R. Kalayarasan, and P. Sakhuja, "Minimally invasive versus the conventional open surgical approach of a radical cholecystectomy for gallbladder cancer: a retrospective comparative study," HPB: The Official Journal of the International Hepato Pancreato Biliary Association, vol. 17, no. 6, pp. 536-541, 2015.

[15] S. Palanisamy, N. Patel, S. Sabnis et al., "Laparoscopic radical cholecystectomy for suspected early gall bladder carcinoma: thinking beyond convention," Surgical Endoscopy, vol. 30, no. 6, pp. 2442-2448, 2016.

[16] Y. S. Yoon, H. S. Han, J. Y. Cho et al., "Is laparoscopy contraindicated for gallbladder cancer? A 10-year prospective cohort study," Journal of the American College of Surgeons, vol. 221, no. 4, pp. 847-853, 2015.

[17] A. A. Gumbs and J. P. Hoffman, "Laparoscopic radical cholecystectomy and Roux-en-Y choledochojejunostomy for gallbladder cancer," Surgical Endoscopy, vol. 24, no. 7, pp. 1766-1768, 2010.

[18] M. A. Machado, F. F. Makdissi, and R. C. Surjan, "Totally laparoscopic hepatic bisegmentectomy $(\mathrm{s} 4 \mathrm{~b}+\mathrm{s} 5)$ and hilar lymphadenectomy for incidental gallbladder cancer," Annals of Surgical Oncology, vol. 22, Supplement 3, pp. S336-S339, 2015.

[19] M. T. Hueman, C. M. Vollmer Jr, and T. M. Pawlik, "Evolving treatment strategies for gallbladder cancer," Annals of Surgical Oncology, vol. 16, no. 8, pp. 2101-2115, 2009.

[20] T. M. Pawlik, A. L. Gleisner, L. Vigano et al., "Incidence of finding residual disease for incidental gallbladder carcinoma: implications for re-resection," Journal of Gastrointestinal Surgery, vol. 11, no. 11, pp. 1478-8611, 2007, discussion 1486-1487.

[21] S. P. Shih, R. D. Schulick, J. L. Cameron et al., "Gallbladder cancer: the role of laparoscopy and radical resection," Annals of Surgery, vol. 245, pp. 893-901, 2007.

[22] A. Cavallaro, G. Piccolo, M. Di Vita et al., "Managing the incidentally detected gallbladder cancer: algorithms and controversies," International Journal of Surgery, vol. 12, Supplement 2, pp. S108-S119, 2014.

[23] Y. Ogura, R. Mizumoto, S. Isaji, T. Kusuda, S. Matsuda, and M. Tabata, "Radical operations for carcinoma of the gallbladder: present status in Japan," World Journal of Surgery, vol. 15, no. 3, pp. 337-343, 1991.

[24] S. H. Kim, J. U. Chong, J. H. Lim et al., "Optimal assessment of lymph node status in gallbladder cancer," European Journal of Surgical Oncology, vol. 42, no. 2, pp. 205-210, 2016.

[25] E. H. Jensen, A. Abraham, E. B. Habermann et al., "A critical analysis of the surgical management of early stage gallbladder cancer in the United States," Journal of Gastrointestinal Surgery, vol. 13, 722 pages, 2009727 pages, 2009.

[26] Y. Murakami, K. Uemura, T. Sudo et al., "Is para-aortic lymph node metastasis a contraindication for radical resection in biliary carcinoma?" World Journal of Surgery, vol. 35, no. 5, pp. 1085-1093, 2011.

[27] G. Piccolo, M. Di Vita, A. Cavallaro et al., "Lymph node evaluation in gallbladder cancer: which role in the prognostic and therapeutic aspects. Update of the literature," European Review for Medical and Pharmacological Sciences, vol. 18, 2 Supplement, pp. 47-53, 2014.

[28] K. Z'graggen, S. Birrer, C. A. Maurer, H. Wehrli, C. Klaiber, and H. U. Baer, "Incidence of port site recurrence after laparoscopic cholecystectomy for preoperatively unsuspected gallbladder carcinoma," Surgery, vol. 124, no. 5, pp. 831-838, 1998.

[29] A. V. Maker, J. M. Butte, J. Oxenberg et al., "Is port site resection necessary in the surgical management of gallbladder cancer?" Annals of Surgical Oncology, vol. 19, no. 2, pp. 409-417, 2012.

[30] D. Fuks, J. M. Regimbeau, P. Pessaux et al., "Is port-site resection necessary in the surgical management of gallbladder cancer?" Journal of Visceral Surgery, vol. 150, no. 4, pp. 277-284, 2013. 


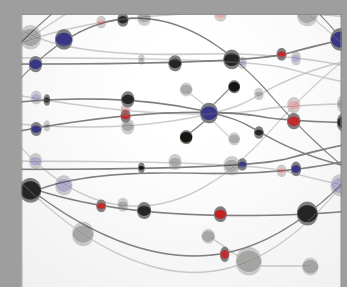

The Scientific World Journal
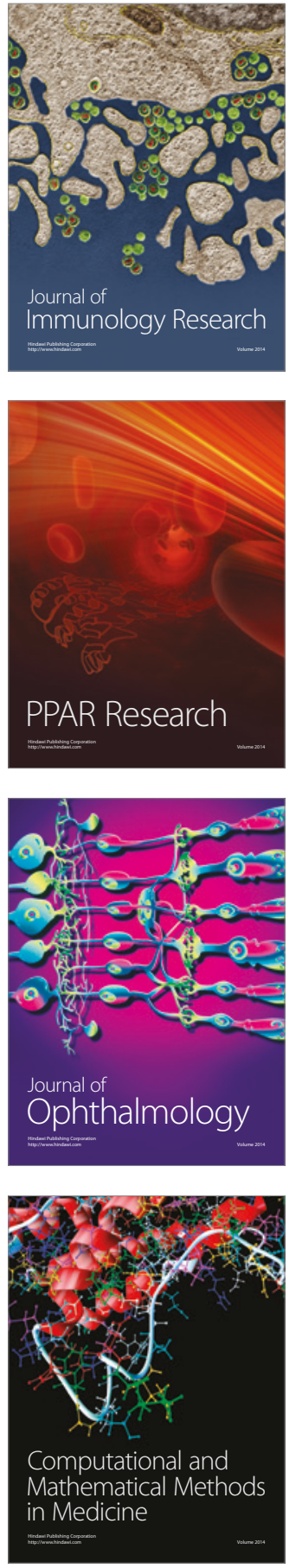

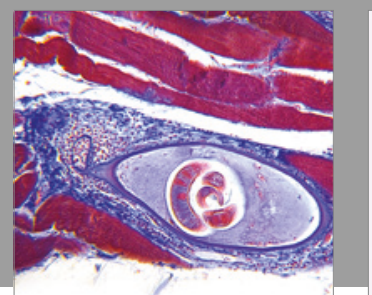

Gastroenterology Research and Practice
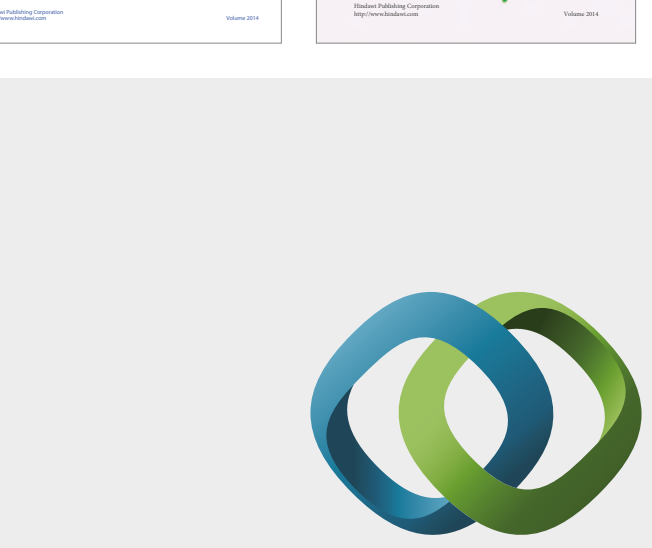

\section{Hindawi}

Submit your manuscripts at

https://www.hindawi.com
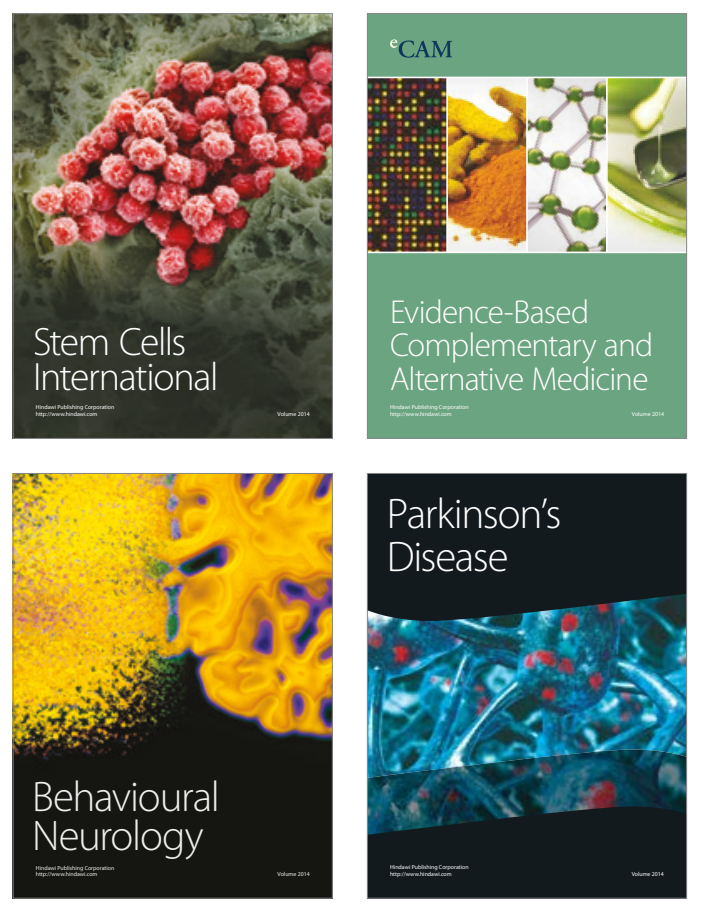
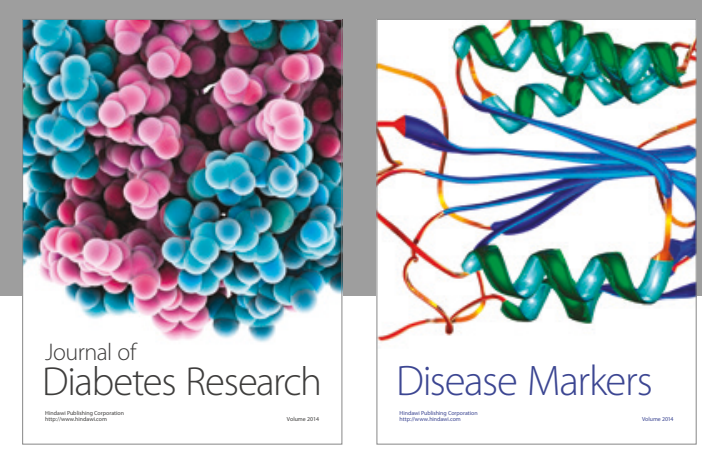

Disease Markers
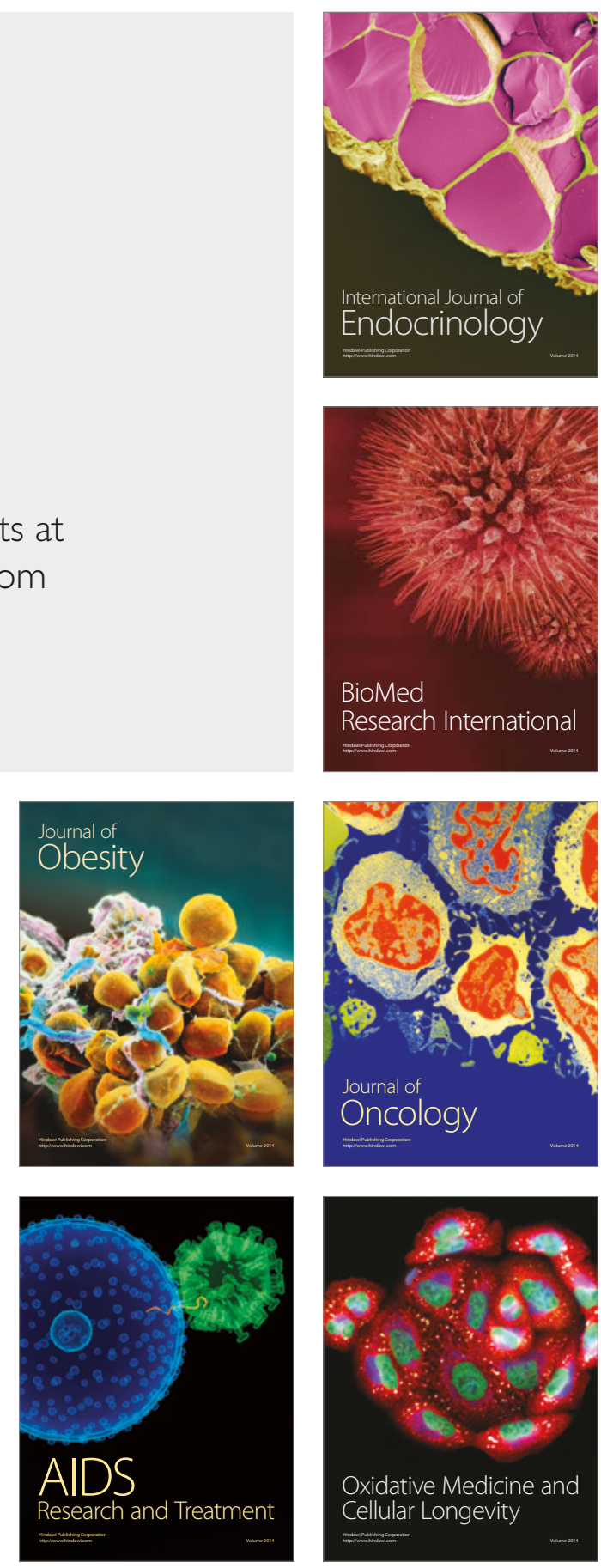